\title{
CONGRÉS INTERNACIONAL IBN AL-ABBĀR I EL SEU TEMPS (ONDA)
}

\author{
Por \\ LUIS FERNANDO BERNABÉ PONS
}

Del 20 al 22 de febrer de 1989 es va celebrar a Onda (Castelló) un Congrés. Internacional sobre la figura del escriptor i historiador andalusi lbn-Al-Abbār, organitzat científicament per la Divisió Departamental d'Estudis Árabs i Islámics de la Universitat d'Alacant i patrocinat per la Conselleria de Cultura de la Generalitat Valenciana (dins dels actes del 750 aniversari), Diputació de Castelló, Ajuntament d'Onda, Caja Rural de Onda i el programa interministerial «Al-Andalus-92».

Nascut a València al segle XIII, Ibn-Al-Abbär va ser un testimoni important de la caiguda de València a mans de Jaume I, que va reflectir en un famós poema. Les seues obres historiogràfiques, escrites durant el seu exili de Tunis, donen notícia d'esdeveniments i personatges andalusins destacats i que per la seua importància mereixjen ser recordats.

Van intervenir en la sessió inaugural del congrés el secretari d'aquest, Jesús Huguet, l'll.Im Sr. alcalde d'Onda, l'Exm. Sr. Ambaixador de Tunis - que en la seua intervenció en àrab va glossar la importància del Congrés com una eina d'unió cultural hispano-àrab-, i el M. Hon. Sr. President de la Generalitat Valenciana, Joan Lerma, que va remarcar el fet d'estudiar el nostre passat àrab i va declarar oficialment inaugurat el Congrés.

La ponència inaugural fou pronunciada per la Dra. M. ${ }^{a}$ Jesús Rubiera Mata, Catedràtica d'Estudis Àrabs i Islàmics de la Universitat d'Alacant, que, sota el títol «lbnAl-Abbār i el seu temps» va emmarcar la figura del polígraf andalusí en el temps agitat que li va tocar viure, donant les coordenades exactes de la seua trajectòria vital $\mathrm{i}$ intel.lectual.

Les següents comunicacions van tenir lloc per la vesprada a l'església medieval de Santa Margarita i totes seguien la mateixa orientació consistent a extraure i analit- 
zar diferents temes al llarg de les obres bio-bliogràfiques d'Ibn-Al-Abbār. Foren pronunciades tres comunicacions en aquest sentit. «Familias andalusíes en la Hulla de Ibn-Al-Abbār», per la Dra. Manuela Marín, «Las lecturas coránicas en Al-Andalus (ss. V/XI-VII/XIII) a través de la Takmila de Ibn-Al-Abbār», per Francisco Rodríguez Maña i «Obras y transmisiones de Hadit (ss. V/XI-VII/XIII) de la Takmila de Ibn-AlAbbār», per la Dra. M. ${ }^{a}$ Isabel Fierro, tots tres membres del C.S.I.C. de Madrid.

El dia següent va tenir lloc la ponència del Dr. Muhammad Bencherifa, de la Universitat de Rabat (Marroc), sota el títol «Alaqa Ibn-Al-Abbār bisayyid Abī Zayd» (La relació entre Ibn-Al-Abbār i el governador Abū-Zayd), que va tractar sobre las relacions politiques a l'època d'Ibn-Al-Abbār. Després d'una petita pausa, el Dr. Djomaa Cheikha, de la Universitat de Tunis, va parlar sobre la poesia d'Ibn-Al-Abbār amb la seua ponència "Al-qīma al-watāiqiqiyya fi dīwān Ibn-Al-Abbār» (El valor documental dins l'obra poètica d'lbn-Al-Abbār). Va tancar la sessió del matí el Dr. AbdelHakim el-Gafsi, del Centre d'Etudes Hispano-Andalouses (Tunis), amb una ponència que portava el títol de «Tunis à l'époque d'Ibn-Al-Abbar: Une active princesse hispanique et les cimetières tunisois».

Per la vesprada van intervenir, en primer lloc, Muhammad Meouak de la Universitat de Lyon, que es va centrar en una obra concreta d'Ibn-Al-Abbar amb la seua ponència «La Hullat al-Siyarā d'Ibn-Al-Abbar: sources et données historiques». Després el Dr. Rached Limam de la Universitat de Tunis en un pla més general va parlar d'aspectes històrics i socio-politics de l'exili tunisenc en la seua ponència «lbn-AlAbbār wa-'asrū-hu fĩ Tūnis» (Ibn-Al-Abbār i el seu temps a Tunis).

El darrer dia del Congrés les ponències van començar amb dues aplicacions pràctiques en l'estudi de les obres d'Ibn-Al-Abbār fent una selecció d'uns personatges determinats i aixi demostrar l'actualitat i l'interés científic del poligraf hispano-àrab: Luis F. Bernabé Pons amb «Personajes de Elche en las obras de Ibn-Al-Abbãr» i Llúcia Martín amb «Personatges d'Onda biografiats per Ibn-Al-Abbār», tots dos de la Universitat d'Alacant. Va tancar la primera part de la sessió el Dr. Slimane-Mustafa Zbiss del Centre d'Etudes Hispano-Andalouses (Tunis), amb la ponència «lbn-AlAbbār et Ibn-Amîra d'Alzira", que va assenyalar el paral.lel entre la vida i obra d'ambdós escriptors andalusins.

Les darreres ponències del matí estigueren a cárrec de la Dra. M. ${ }^{a}$ Luisa Ávila, de la Escuela de Estudios Árabes del C.S.I.C. de Granada, que va parlar d'una de les fonts de les obres d'Ibn-Al-Abbār amb la seua comunicació «lbn Hārit, fuente de Ibn-Al-Abbār» i el Dr. Luis Molina, de la mateixa Escuela de Estudios Árabes, que va tractar d'Ibn-Al-Abbār com a font d'estudis històrics posteriors amb la seua intervenció «lbn-Al-Abbār, fuente para la historia de Al-Andalus».

Les ponències finals tingeren lloc per la vesprada i foren pronunciades pel Dr. Míkel de Epalza, de la Divisió Departamental d'Estudis Àrabs i Islàmics de la Universitat d'Alacant, que va parlar del paper primordial d'Ibn-Al-Abbār com historiador d'Al-Andalus en la seua ponència «La pèrdua de València i altres pèrdues d'Al-Andalus segons Ibn-Al-Abbār»".

La darrera comunicació portava el títol «Política de Jaime I en relación con la población musulmana en los años de la conquista del Reino de Valencia” i va ser pronunciada per Vicent Garcia Edo. Hi va tractar el tema de la conquesta des del punt de vista cristià. 
Al voltant del Congrés es van desenvolupar una sèrie d'activitats extra-acadèmiques relacionades amb el tema central: exposicions bibliogràfiques, visita al castell d'Onda, etc.

Les ponències en llengua àrab van ser traduïdes de forma simultània pel Dr. Marcelino Villegas, de la Divisió Departamental d'Estudis Àrabs i Islàmics de la Universitat d'Alacant, treball que fou destacat i lloat per tots els congressistes assitents.

Va tancar el Congrés la lectura de les conclusions per part de la Dra. Rubiera, en les quals es valorava positivament el treball portat a terme i s'encoratjava a les institucions $i$ als investigadors a realitzar en properes ocasions activitats com la que ara finalitzava. A l'acte de cloenda van intervenir el secretari del Congrés, l'll.Im. Sr. Alcalde d'Onda i el Sr. Director General del Patrimoni Cultural, Enric Cunyat, que va declarar oficialment clausurat el Congrés.

Les actes d'aquest congrés seran publicades per la Conselleria d'Educació i Ciència de la Generalitat Valenciana. 